Revista de Economia Política, vol. 20, nº 1 (77), pp. 52-74, janeiro-março/2000

\title{
União Monetária Europeia - UME: Evolução Recente e Perspectivas
}

European Monetary Union: Recent evolution and perspectives

RICARDO DA COSTA NUNES* SELENE PERES PERES NUNES**

RESUMO: Este artigo discute a singularidade e a estabilidade do modelo proposto para a União Monetária Europeia - UEM, apontando algumas das dificuldades enfrentadas em sua implementação e as chances de superá-las. Também sugere como todos os pontos da integração monetária europeia - independência do banco central, orçamento equilibrado e estabilidade da taxa de câmbio dentro de uma certa faixa de flutuação - são sustentados com a proposta de que a economia funda o auto-ajuste, pois há flexibilidade de salários e preços e a intervenção do Estado permanece o mais curta possível. Assim, a necessidade de convergência do critério econômico e financeiro da UEM e a suficiência de sua conquista para um maior desenvolvimento da Europa diante de outros países trazem a discussão de volta ao paradigma teórico.

PALAVRAS-CHAVE: União Europeia; união monetária; integração econômica; Euro

ABSTRACT: This paper discusses the uniqueness and the stability of the proposed model for the European Monetary Union - EMU, pointing out some of the difficulties faced in its implementation and the chances of surpassing them. It also suggests how all the points of European monetary integration - central bank independence, balanced budget and stability of the exchange rate within a certain band of fluctuation - are sustained upon the proposition that economy founds auto-adjustment since there is flexibility of wages and prices and the State's intervention remains as short as possible. Thus, the need of convergence of economic and financial EMU's criterion and the sufficiency of its achievement to a greater development of Europe in face of other countries bring the discussion back to the theoretical paradigm.

KEYWORDS: European Union; monetary union; economic integration; Euro.

JEL Classification: F45; F42; F33.

\footnotetext{
* Secretaria do Tesouro Nacional/MF, cedido para a Secretaria de Assuntos Internacionais do Ministério de Planejamento, Orçamento e Gestão/MP.

* Secretaria do Tesouro Nacional/MF, cedida para a Assessoria Econômica do Ministério de Planejamento, Orçamento e Gestão/MP.
} 
"He that does not apply new remedies must expect new evils, for time is the greatest innovator."

Francis Bacon

\section{INTRODUCÃO}

Os anos 80 e 90 têm assistido, em todo o mundo, a um movimento de redução da participação do Estado na economia, tanto por parte dos formuladores de política econômica como pela corrente de pensamento predominante no meio acadêmico - o mainstream. A polémica gerada em torno da União Monetária Europeia (UME) insere-se nesse contexto por retomar algumas questões teóricas básicas relacionadas à unicidade e à estabilidade do modelo de política econômica proposto.

Todos os pontos da pauta da integração monetária europeia - a tese de independência do Banco Central, a busca de equilíbrio orçamentário e a estabilidade do câmbio dentro de determinada faixa de variação - parecem apoiar-se na proposição de que a economia se auto-ajustará desde que haja flexibilidade de salários e preços e a intervenção do Estado seja a menor possível. Assim, se a concepção de crise abrange apenas o universo das variáveis nominais, basta perseguir a estabilização de preços através da adoção de políticas fiscal, monetária e cambial restritivas, o que afasta a possibilidade de utilização da política econômica para fomentar o crescimento do produto e do emprego.

Essa proposição conduziu a uma guinada na definição da política econômica mundial, relativamente à situação vivenciada nos anos 50 e 60, quando a política fiscal, inspirada por Keynes, determinava o crescimento da economia. Postulava-se, nessa época, que cabia ao governo fazer com que a política monetária se acomodasse aos objetivos fiscais, gerando liquidez, garantindo juros baixos e, com isso, ajudando o crescimento. Contrariamente, agora passou a haver um largo consenso, entre os países desenvolvidos, de que a política econômica deve ser neutra.

Do prognóstico de política monetária neutra, presente em Ricardo (1821), Friedman (1984) e Lucas \& Sargent (1981), subentende-se que a política econômica pode apenas desviar transitoriamente o produto e o emprego da sua posição de equilíbrio, a qual converge para a taxa natural de desemprego. Segundo Friedman (1984: 21-2): "Fundamentalmente, só há dois meios de coordenar as atividades econômicas de milhões. Um é a direção central utilizando coerção [ ...]. O outro é a cooperação voluntária dos indivíduos à técnica de mercado. A possibilidade da coordenação, por meio da cooperação voluntária, está baseada na proposição elementar - no entanto frequentemente negada — de que ambas as partes de uma transação econômica se beneficiam dela, desde que a transação seja bilateralmente organizada e voluntária."

Contudo, conforme afirmam Tuchscherer (1981), Isaac (1993) e Carvalho (1995), a maior parte dos trabalhos teóricos que propõem a independência do Banco Central incorpora a hipótese de taxa natural de desemprego e os resultados monetaristas, princípios que não são universalmente aceitos. 
O objetivo deste trabalho é discutir as dificuldades de implementação da integração monetária europeia e suas chances de superação.

O primeiro ponto a ser discutido, então, refere-se à necessidade de convergência dos indicadores econômicos e financeiros para o sucesso da UME. Assim, a primeira seção descreve a proposta da UME e apresenta as razões pelas quais tem sido buscada como forma de retomar o desenvolvimento da Europa vis-à-vis a outros países.

O segundo ponto diz respeito à estabilidade dos critérios da UME e às dificuldades inerentes a sua manutenção. Na segunda seção, são apresentados alguns dos obstáculos enfrentados pela proposta de independência do Banco Central. Uma das críticas aponta o conflito entre os objetivos de manter o poder de compra da moeda e assegurar a credibilidade do sistema financeiro como elemento inviabilizador da implementação de regras monetárias rígidas. A terceira seção mostra que a busca do equilíbrio orçamentário e a proposta de federalização exigem que se obtenha uma coalizão em torno do ajuste fiscal e que sejam superadas diferenças econômicas e políticas em prol de um modelo político-decisório mais centralizado para a Europa. A resistência ao ajuste fiscal por esse meio reuniu fortes opositores e contra-argumentos teóricos os mais diversos porque envolve questões técnicas e políticas, notadamente relacionadas à soberania nacional dos países europeus. $\mathrm{Na}$ quarta seção, analisa-se a possibilidade de obtenção de níveis estáveis de câmbio dentro de determinada faixa de variação e algumas das críticas formuladas à prescrição cambial da UME. A flexibilidade de salários e preços como pré-condição ao livre fluxo de trabalho e capital e, consequentemente, à obtenção dos critérios de Maastricht é objeto da quinta seção.

Por fim, a conclusão do trabalho discute as perspectivas e a suficiência da adequação aos critérios da UME, o que retoma a questão do paradigma teórico. Discute-se se, vencidas as resistências iniciais, a UME seria estável e se a adequação aos critérios garantiria que fosse atingido, de forma sustentável, o objetivo de maior desenvolvimento dos países europeus.

\section{A PROPOSTA DA UME: O QUE É E POR QUE É NECESSÁRIA}

Criada pelos países-membros da União Europeia (UE) no Tratado de Maastricht de 1991, a UME é o resultado de quarenta anos de esforços comuns para consolidar a união da Europa e reduzir as desigualdades regionais. Esse processo teve início em março de 1957, com o Tratado de Roma que, em continuidade à Comunidade Europeia do Carvão e do Aço, formalizou a adesão dos primeiros seis países - Bélgica, França, Itália, Luxemburgo, Países Baixos e Alemanha. Em seguida, várias iniciativas agregaram-se: livre-mercado, política agrícola comum, adesão de novos países, definição da carta social e criação do sistema monetário europeu.

O objetivo da UME é aumentar a prosperidade dos países europeus e, em especial, reverter a queda das exportações europeias para o mundo e aumentar o comercio entre suas fronteiras em substituição ao comércio com outros países, em 
um momento em que é indispensável adaptar-se às exigências ditadas pela globalização dos mercados e pela inserção competitiva da Europa no cenário internacional. O aumento do comércio entre os países da UME e destes com o resto do mundo ocorreria com a troca dos mercados individuais de reduzida dimensão por mercados mais amplos, cujos produtores se beneficiariam da supressão dos custos de câmbio e da queda de custos do trabalho.

Os critérios de participação na integração monetária estão definidos pelo acordo de Maastricht. Foram estabelecidos índices estritos de convergência das taxas de inflação e de juros, do déficit orçamentário, do nível da dívida, fixando ainda as taxas de câmbio entre os países-membros: déficit orçamentário de, no máximo, $3 \%$ do PIB; dívida pública máxima de $60 \%$ do PIB; inflação anual de, no máximo, $1,5 \%$ acima da média dos três países com menor inflação; juros de longo prazo não superiores a $2 \%$ da média dos juros de longo prazo nos três países europeus com inflação mais baixa; manutenção, nos dois últimos anos, da moeda nacional na margem de flutuação do sistema monetário europeu, sem desvalorizações; e independência do Banco Central dos governos nacionais. Num segundo momento, em $1{ }^{0}$ de janeiro de 1999 , está também prevista a conversão das moedas nacionais em euro. Apenas em 2002 deve ocorrer a emissão de euros.

Para assegurar que os países membros não realizarão uma política econômica que comprometa a saúde fiscal, cambial e monetária, o que poderia resultar no descontrole monetário, a UME determinou o "pacto de estabilidade", projetado para manter a convergência dos indicadores econômicos e financeiros depois do lançamento da divisa única.

O primeiro ponto a ser discutido, então, refere-se à necessidade de convergência dos indicadores econômicos e financeiros para o sucesso da UME. Os defensores da UME argumentam que, numa economia globalizada e que crescentemente exige maior competitividade, não há alternativa para retomar o desenvolvimento da Europa vis-à-vis a outros países.

De fato, desde o fim da Segunda Guerra Mundial, a Europa vem perdendo o papel de potência econômica à medida que outros países, como EUA e Japão, tomam gradativamente o espaço europeu no mundo. Neste contexto, a UME surge como uma tentativa de conseguir o que os governos nacionais isoladamente não conseguem: recuperar o prestígio da Europa no mundo. Goodhart (1996) também reconhece que a unificação monetária pode propiciar ganhos econômicos: "There is no question in my mind that a single currency does strengthen a single market" (p. 1087). ou ainda: "I separate currencies tend to lead to separate commercial policies and trade barriers of some kind or another" (p. 1087).

A necessidade de a Europa buscar o aumento do comércio dentro de suas fronteiras é confirmada pelo fato de os países membros da UE virem perdendo presença no comércio mundial. Entre 1991 e 1996, a participação das exportações da Alemanha, França, Itália e Reino Unido diminuiu, enquanto nos EUA se man- 
teve constante e no Japão aumentou. Além disso, de 1979 a $1998^{1}$, as exportações da UE cresceram menos que as dos EUA e do Japão, conforme tabelas a seguir.

Seleção de Alguns Países da União Monetária Europeia-UE, EUA e Japão:

Percentuais de Exportações sobre Exportações Mundiais

\begin{tabular}{lccccccccc}
\hline Países & 1990 & 1991 & 1992 & 1993 & 1994 & 1995 & 1996 & $1997^{*}$ & $1998^{*}$ \\
\hline EUA & 11,6 & 12,2 & 12,1 & 12,4 & 12,1 & 11,7 & 11,8 & 12,5 & 12,3 \\
Japão & 8,5 & 9,1 & 9,3 & 9,8 & 9,6 & 9,0 & 8,0 & 7,9 & 8,1 \\
Alemanha & 12,1 & 11,6 & 11,8 & 10,4 & 10,4 & 10,4 & 10,3 & 9,8 & 9,7 \\
França & 6,3 & 6,2 & 6,4 & 5,7 & 5,6 & 5,7 & 5,6 & 5,3 & 5,3 \\
Itália & 5,0 & 4,9 & 4,8 & 4,6 & 4,5 & 4,7 & 4,8 & 4,6 & 4,4 \\
Reino Unido & 5,4 & 5,3 & 5,2 & 4,8 & 5,0 & 4,9 & 5,0 & 5,2 & 5,1 \\
\hline
\end{tabular}

Fonte: OECD, junho 1997

* Previsão

\begin{tabular}{c|ccccccccccccc}
\hline \multicolumn{10}{c}{ UNIÃO EUROPÉIA, EUA E JAPÃO } \\
\hline \multicolumn{10}{c}{$\begin{array}{c}\text { Volume de Exportação } \\
\text { (variação percentual anual) }\end{array}$} \\
\hline Países & Média & $1979-88$ & 1989 & 1990 & 1991 & 1992 & 1993 & 1994 & 1995 & 1996 & 1997 & 1998 & $\begin{array}{c}\text { Acumulado } \\
1979-98\end{array}$ \\
\hline EUA & 5,5 & 11,7 & 8,5 & 6,3 & 6,6 & 2,9 & 8,2 & 8,9 & 6,5 & 7,3 & 6,8 & $174 \%$ \\
Japão & 5,7 & 9,1 & 6,9 & 4,4 & 4,9 & 1,2 & 4,6 & 5,4 & 2,2 & 8,1 & 7,8 & $145 \%$ \\
UE & 3,9 & 7,8 & 6,8 & 23 & 4,4 & 2,3 & 8,3 & 7,3 & 4,7 & 6,6 & 6,3 & $125 \%$ \\
\hline
\end{tabular}

Fonte: FMI, 3997

O custo do trabalho europeu é mais elevado e vem apresentando maiores taxas de crescimento do que nos países concorrentes. Além disso, entre 1979 e 1995, o crescimento da produtividade da mão-de-obra europeia foi de $1,1 \%$ a.a., enquanto no Japão alcançou 1,2\% a.a., o que torna ainda mais oneroso o já elevado nível dos trabalhadores na UE. Comportamento semelhante é observado relativamente à oferta de benefícios aos trabalhadores, que também é superior em nível e em taxa de crescimento à da maioria dos trabalhadores japoneses e americanos. $\mathrm{Na}$ Alemanha, por exemplo, os custos trabalhistas têm tornado o país pouco atraente ao capital estrangeiro e ao doméstico, pois o capital tende a afluir para países onde o custo de produção é menor, o que afeta a realização de investimentos e o nível de exportações. Estatísticas divulgadas em julho de 1996 pelo Bundesbank mostraram que os investimentos diretos externos na Alemanha em 1995 foram de US\$ 8,4 bilhões e os investimentos alemães no exterior foram US\$ 32 bilhões.

O alto custo da mão-de-obra estimula, ainda, a substituição do trabalho por

\footnotetext{
${ }^{1}$ Utilizando previsões do FMI.
} 
capital no processo produtivo fazendo com que o aumento da taxa de crescimento dos países europeus não seja acompanhado pela geração de empregos (jobless growth). Assim, o crescimento do produto da UE passou de 2,9\% em 1990 para $3,4 \%$ em 1995, enquanto a taxa de desemprego aumentou de 8,4\% em 1990 para 11,5\% em 1995.

Além de dificultar o crescimento do produto devido à perda de mercados e à queda da relação emprego/produto, o alto custo da mão-de-obra também impede que se amplie o volume de arrecadação fiscal, ao mesmo tempo que consome boa parte dos recursos arrecadados com impostos. Talvez seja esta a explicação para o fato da UE ter apresentado taxas de crescimento menores que as da economia norte-americana.

\section{A PROPOSTA DE INDEPENDÊNCIA DO BANCO CENTRAL}

A proposta de criação de um Banco Central europeu independente teve origem na percepção do potencial instabilizador da política monetária de alguns países para suas próprias economias e para as demais e, portanto, para a integração europeia. Teoricamente, déficits fiscais podem ser financiados por emissão de títulos da dívida interna ou externa e por financiamento monetário, o qual compreende receita de seignorage e imposto inflacionário. A ideia central é que, se o Banco Central de um país não é independente, esse governo pode utilizar o financiamento da política monetária para realizar uma política fiscal expansionista, o que tende a elevar os níveis de produto e emprego e gerar inflação. Esse comportamento é bastante provável em países com elevado nível de desemprego e no ciclo político, isto é, nas proximidades das eleições, quando o governo procura atingir maiores índices de popularidade para perpetuar-se no poder. Portanto, a proposta de independência do Banco Central europeu caminha no sentido de evitar o financiamento monetário, o que se coaduna com o objetivo de manter sob controle os déficits fiscais.

Para Hagen \& Süppel (1994), quando da criação do Banco Central europeu deve-se evitar que a distribuição de poderes entre os membros e a administração central aumente o poder de decisão dos estados nacionais porque estes corroeriam a estabilidade da política monetária. Ou seja, não bastaria criar um Banco Central europeu, mas torná-lo independente para que ficasse isento das pressões políticas dos governos nacionais: "In a federal monetary union, leaving the decision over monetary stabilization policies to the representatives of the individual countries always leads to inefficient monetary stabilization. The two reasons for this are that these representatives Will want to use the common monetary policy to stabilize regional shocks, and that they face a greater degree of policy uncertainty making their response to aggregate shocks inappropriately small”.

Teoricamente, a proposta de independência do Banco Central é sustentada pelo paradigma que atribui às variáveis nominais e à ingerência do governo na economia a responsabilidade pelo surgimento de crises. Neste contexto, o novo 
papel do Banco Central, de condutor de uma política monetária restritiva, tornouo mais suscetível a pressões políticas. A fixação de metas monetárias rígidas seria, então, a garantia de inflação baixa pois as decisões de política monetária seriam transferidas para as mãos de tecnocratas não-eleitos. Para Barro (1996) e Shah (1997), apenas um Banco Central independente e comprometido com o controle da inflação que implemente regras monetárias rígidas, pode assegurar a estabilidade dos preços.

Esse argumento é impulsionado pela experiência histórica da Alemanha, onde a defesa da moeda e a conhecida aversão ao crescimento dos preços são explicadas pelo fato do descontrole do crédito do Reichsbank ao governo ter sido um dos fatores que ocasionou a hiperinflação de 1923. A integração monetária é um fator de preocupação para o eleitor alemão que teme que a estabilidade do seu país seja contaminada pela fragilidade das finanças públicas de economias como a italiana: "Die machen unser schônes Geld kaputt" (elas destroem nosso belo dinheiro).

A tese da independência do banco central encontra, no âmbito da UME, críticas semelhantes às que são apresentadas no caso de um país específico. O primeiro argumento - o econômico - depende de que a atuação do Banco Central seja capaz de assegurar o comportamento dos preços.

Neste ponto, há questões ainda pouco equacionadas no âmbito da UME. A busca de uma união comercial superavitária, por exemplo, pode ter efeitos monetários consideráveis. O aumento de reservas poderá ser um fator de expansão monetária se os superávits comerciais almejados não forem compensados por equivalente saída de capitais.

Um outro empecilho à estabilidade monetária e cambial da UME que vem sendo apresentado por autores como Goodhart (1996) e Carvalho (1995) diz respeito ao conflito de objetivos do Banco Central que podém inviabilizar a sua independência nos termos propostos. Segundo estudo empírico de Goodhart (1994), o objetivo de perseguir a estabilidade de preços e o poder de compra da moeda freqüentemente conflita com o de assegurar a credibilidade do sistema financeiro. A atuação do Banco Central como emprestador de última instância, na França e na Itália, por exemplo, teria motivado o Banco Central a realizar empréstimos a bancos falidos ou concedido crédito a outros bancos que os assumissem ${ }^{2}$, impactando a base monetária e comprometendo o controle da inflação, em conflito com a adequação aos critérios da UME.

A articulação da criação de uma agência específica de controle sobre o sistema financeiro - um controller distinto do BC surgiu como proposta na UME na tentativa de separar as funções do Banco Central. O problema é que separar a gestão não elimina o conflito macroeconômico: de qualquer modo, ainda que por intermédio de agentes distintos, o governo estaria enxugando a liquidez por um lado e expandindo bor outro.

\footnotetext{
${ }^{2}$ No Brasil, a experiência recente de assistência financeira denominada PROER também objetivou a salvaguarda do sistema financeiro.
} 
O estudo de Goodhart (1994) conclui ainda que países com Bancos Centrais independentes podem ser tão eficientes no atendimento de metas de inflação quanto países em que o Banco Central é subordinado ao Executivo. O resultado seria antes atribuível à credibilidade da política econômica e do próprio Banco Central.

$\mathrm{O}$ segundo argumento - político - depende de que a independência do BC seja capaz de libertá-lo de pressões políticas. Contudo, se quem define o objetivo de inflação não é o Banco Central mas o governo eleito, como propôs recentemente o governo inglês, não se pode dizer que as metas monetárias tenham deixado de ser influenciadas por pressões políticas. No máximo, elas podem ter passado a depender do Congresso. Em outras palavras, se o Banco Central tem apenas a autonomia operacional para executar sua tarefa, a substituição do Executivo pelo Legislativo no processo decisório pode não ser garantia de isenção. De acordo com De Grauwe (1996), mesmo que o Banco Central europeu seja independente, as pressões políticas não deixarão de existir: "The European Central Bank Will be composed of representatives of the participating countries. Even if the ECB is made independent these representatives may still have different inflation preferences".

Além disso, no caso da UME, a rede de pressões políticas atinge o relacionamento entre países. O Banco Central inglês, por exemplo, vem discutindo com os demais Bancos Centrais europeus as condições de acesso do país ao sistema eletrônico europeu de compensação de pagamentos, temendo que uma exclusão do processo prejudique a posição de Londres de centro financeiro ${ }^{3}$.

Segundo Herz \& Rôger (1992), a independência do Banco Central europeu, em última instância, conferiria preponderância ao Banco Central alemão - e à política econômica alemã - sobre os demais e acabaria por subjugar a aceitação ou rejeição de um país na UME ao cumprimento dos critérios impostos pela Alemanha: "The Bundesbank dominates the monetary policies of the other EMS member countries". Ou ainda: "[...1 the empirical results clearly indicate German dominance in the monetary policies of Denmark, France, Ireland and Netherlands".

A supremacia alemã na determinação da política econômica, é evidenciada pelo fato de o presidente do Bundesbank insistir na imposição de multas a países que não cumpram o pacto de estabilidade. Essa posição é prevista por De Grauwe (1996): "when two countries with different reputations concerning inflation (say Germany and Italy) decide to form a monetary union, the high inflation country is likely to profit form the reputation of the low inflation country. The converse is also true: the low inflation country Will be 'infected' by the bad reputation of the high inflation country, and will experience a welfare loss. Since the low inflation country, Germany, loses when it joins the unions, it Will not want to do so except if it can impose conditions. These conditions must be that the union central bank should have the same preferences as the German central bank. Thus, this analysis provides the intellectual underpinnings for the Maastricht decision to institute a European Central Bank which is a close copy of the Bundesbank (political independence, price stability as the

${ }^{3}$ Ver Gazeta Mercantil, 17/9/96. 
sole objective of monetary policy)" [...] Majority voting in the Board may then put the German representative in a minority position, so that the equilibrium inflation rate in the union would exceed the German one. In order to avoid this outcome Germany Will want to control the entry into the union, so that only those countries with the same preferences join the union" (p. 1094).

\section{A BUSCA DO EQUILÍBRIO ORÇAMENTÁRIO E A PROPOSTA DE FEDERALIZAÇÃO}

Além do projeto da UME - incluindo o estabelecimento do Banco Central europeu independente e a adoção de bandas de flutuação cambial no período de transição para o euro -, a harmonização da política econômica e orçamentária envolve várias propostas, entre elas uma reforma da política agrícola comum e a expansão do orçamento da UE.

$\mathrm{Na}$ área fiscal, várias têm sido as medidas adotadas para o saneamento das finanças públicas, visando a adequação aos critérios de Maastricht. Na França, por exemplo, podem-se citar o fim de isenções fiscais para os jornalistas, a redução do quadro de funcionários públicos e a diminuição de repasses para a previdência. $\mathrm{Na}$ Alemanha, foi divulgada a manutenção da meta de déficit de $2,5 \%$ do PIB para 1997, abaixo do valor de 3\% estabelecido no Tratado de Maastricht, o que requer redução dos gastos públicos da ordem de US\$ 5,5 bilhões. Em Portugal, o governo enviou ao Parlamento projeto de orçamento fixando meta de déficit público em 2,9\% em 1997, contra 4,3\% estimado para 1996.

UE também vem elaborando normas para regulamentar ajudas estatais a governos subnacionais pois, para assegurar o livre fluxo de capital, é preciso impedir que os governos nacionais concedam subsídios a suas províncias, o que tornaria algumas regiões mais atraentes aos investimentos do que outras. Um esforço neste sentido, é a determinação da UE de limitar o volume de subsídios governamentais à indústria e a tentativa de despolitizar o processo pelo qual a comissão veta essa ajuda, dificultando a influência dos governos sobre o resultado das decisões. Neste sentido, as autoridades da UE estão elaborando propostas para um esquema "multissetorial”, sob o qual qualquer ajuda oficial acima de US\$ 57 milhões seria examinada pela comissão, medida que daria a Bruxelas maior controle sobre os casos mais importantes e distorcidos de ajuda estatal. Atualmente, os governos conseguem subsidiar até $75 \%$ dos investimentos nas regiões menos privilegiadas da UE. Em regiões menos pobres, mas ainda necessitadas, o valor chega a $30 \%$. Pelas propostas a serem apresentadas nos próximos meses aos ministros da Indústria, os tetos seriam reduzidos a $50 \%$ e $20 \%$, respectivamente.

Contudo, uma coalizão definitiva em torno do ajuste fiscal dependeria de aspectos estruturais das economias e de fatores políticos. Um dos pressupostos da UME é que o livre jogo das forças de mercado seria capaz não só de promover o crescimento sustentado - através, por exemplo, da expansão de mercados - como de reduzir as desigualdades regionais. No entanto, as grandes disparidades de ren- 
da e emprego entre os países tenderiam a criar pressões políticas em prol da adoção de uma política desenvolvimentista. Em regimes democráticos, os governos precisam do apoio da população para se perpetuarem no poder, o que faz com que a conciliação entre os objetivos da UME e dos governos nacionais dependa da difícil harmonização entre economia e política.

Uma das propostas mais polêmicas na área fiscal diz respeito à federalização, um modelo político-decisório com forte centralização e três objetivos básicos: assegurar o ajuste das contas públicas, reduzir as desigualdades regionais e contribuir para o livre fluxo de capital.

A federalização da Europa evitaria que os orçamentos nacionais ficassem sujeitos a pressões políticas por maiores gastos, o que poderia comprometer a adequação aos critérios de Maastricht, inclusive no que se refere ao nível de endividamento. O sistema atual padece dos mesmos problemas observados nas federações, e já constatados por autores como Ter-Minassian (1997) e Tanzi (1996). O que caracteriza uma federação é a existência de competências legislativas tributárias próprias de cada país e execução própria de cada orçamento. O fato de as receitas e despesas fiscais não serem centralizadas determina que o orçamento não possa ser empregado de maneira eficiente como instrumento de estabilização. Na UE, do mesmo modo que nos governos subnacionais dos países federados, os países têm como metas prioritárias a geração de emprego e o atendimento das demandas sociais de seu eleitorado, tais como serviços de saúde, educação e de infra-estrutura e, apenas secundariamente, a estabilização dos preços.

Vale lembrar, contudo, que essa proposição de maior efetividade da política de estabilização quando se atribui maior poder ao governo central é contraposta por autores como Shah (1997), para quem a descentralização fiscal, acompanhada da transferência de recursos e encargos e de um arranjo institucional que assegure o cumprimento da lei orçamentária, pode contribuir mais para a governança econômica que a centralização.

Os defensores da UME argumentam ainda que o orçamento centralizado poderia ser utilizado como instrumento de distribuição de renda e de fomento ao desenvolvimento, para equilibrar regiões em situação econômica diferente. Assim, a federalização tenderia a concorrer para a manutenção dos critérios de Maastricht porque, além da redução dos níveis de endividamento e inflação, com a integração fiscal, haveria também uma contribuição maior para o desenvolvimento econômico de regiões mais pobres dos países mais atrasados. Uma iniciativa para reduzir as desigualdades econômicas na UE diz respeito ao Fundo de Coesão, cuja função é estimular o desenvolvimento nas regiões menos prósperas.

Contudo, a existência de áreas com níveis de desenvolvimento econômico distintos ameaça a sobrevivência da UME porque a constatação da impossibilidade de trazer desenvolvimento a todos os Estados nacionais e minorar as desigualdades inter e intra-governamentais faria aflorar as resistências internas. Se o livre jogo das forças de mercado não for suficiente para assegurar o desenvolvimento dos países mais atrasados bem como das regiões mais atrasadas de todos países, as 
regiões pobres recorrerão à intervenção do poder público para alavancar seu crescimento.

A dificuldade de adequação aos critérios de Maastricht é explicada, em parte, pelo fato de as taxas de desemprego dos países europeus divergirem substancialmente, o que cria problemas políticos internos em vários países, com protestos de sindicatos e perda de prestígio da classe política dirigente. Na França, onde o desemprego poderá chegar a $13 \%$ em 1997 , as greves e manifestações populares contra medidas de cortes de gastos sociais têm sido fortes e teme-se que o governo nacional deste e de outros países com elevado índice de desemprego prefira atender as reivindicações populares em detrimento da estabilização da economia. Os franceses desejariam, inclusive, que a taxa de desemprego fosse um critério essencial de performance econômica a ser buscado, em detrimento da "obsessão monetária “ que restringe a possibilidade de utilização de políticas monetária e fiscal contracíclicas. Isto é, nessa concepção de política econômica, as medidas não deveriam atender apenas a objetivos monetários ou financeiros, mas a objetivos mais gerais de política econômica, o que tenderia a equilibrar as tendências monetaristas em favor do atendimento a reivindicações sociais.

A tendência de crescimento da despesa pública foi explicada por autores da escola de modelos de interações político-econômicas. Segundo Passarides (1980), por exemplo, o governo intervém objetivando alcançar índices de popularidade que lhe permitem permanecer no poder. Assume-se que os índices de popularidade crescem com a queda do nível de desemprego e o crescimento da renda disponível. Assim, o fato de a política fiscal e a publicidade das obras do governo serem utilizadas como instrumento de ação política do governo dificultaria o apoio à proposta de federalização.

Esta posição é compartilhada pelo ex-primeiro ministro Major que demonstrou ceticismo quanto aos critérios e prazos para a $\mathrm{UME}^{4}$ porque, para que a UME se concretize é necessário que a população dos diversos países a apoie. A Câmara dos Comuns do Parlamento britânico concordou em ratificar o tratado, mas apenas depois de um debate que causou traumas no Partido Conservador, que governava o país. Os dinamarqueses só ratificaram o Tratado de Maastricht depois de um segundo referendo. Os franceses aprovaram-no por margem mínima em seu referendo de setembro de 1992. Até mesmo a Corte Constitucional alemã expressou dúvidas quanto ao Tratado de Maastricht.

A sintonização da política econômica é, portanto, dificultada pelas grandes disparidades de renda e emprego entre os países integrantes, ampliadas pelas diferenças regionais internas. De acordo com Gomes (1997): “Os dados [...] revelam a existência de significativas disparidades regionais na União Europeia, quanto a níveis de produto per capita, composição setorial do emprego. Colocadas num quadro comparativo, as disparidades regionais (especialmente PIB per capita) são maiores que as registradas nos Estados Unidos — tomados como um exemplo de

\footnotetext{
${ }^{4}$ ver Financial Times, 07/01/97.
} 
equidade regional -, e se revelam pequenas diante das que ocorrem no Brasil, exemplo oposto. Muitas outras discrepâncias mereceriam registro, numa visão mais abrangente da diversidade europeia”.

Além das pressões políticas e da discussão em torno da associação entre eficiência e descentralização, parece haver uma inconsistência básica entre a proposta de federalização e a redução das desigualdades regionais. A centralização de gastos pode até ser eficiente para evitar o desajuste das contas públicas dos governos, mas em termos alocativos e distributivos o sistema descentralizado é mais recomendável. Além disso, a ênfase da política econômica na contenção de gastos implica o abandono de qualquer perspectiva de longo prazo a respeito de investimento público. As taxas de juros reais elevadas, promovidas por políticas fiscal e monetária restritivas, por sua vez, também desestimulam os investimentos privados. A redução dos gastos públicos, notadamente com infra-estrutura e produção de tecnologia, e dos investimentos de forma geral, é responsável por taxas de crescimento do produto e do emprego menores, com ou sem mercado de trabalho flexível. Ainda do ponto de vista fiscal, o menor crescimento do produto restringe a arrecadação tributária que poderia contribuir para o saneamento das contas públicas.

Se os governos nacionais deixarem de atribuir aos respectivos orçamentos as funções de geração de emprego, crescimento do produto e satisfação de necessidades sociais, como a UME conseguirá minorar as diferenças regionais sem a força de um orçamento expressivo? A federação brasileira e a italiana, apesar de terem uma moeda única e ainda utilizarem recursos de transferências para estimular o desenvolvimento de áreas mais pobres, não conseguiram minorar as diferenças regionais. Então, por que a UME com dificuldades maiores conseguiria? Este aspecto não passou despercebido a Hoeller, Louppe e Vergriete (1996:5) que apontam o pequeno volume do orçamento: "The EU's budget is very small relative to that of the Member States". Ou ainda: "It is also not large or flexible enough to enable the Community to pursue macroeconomic stabilisation objectives". Para Goodhart (1996: 1.089): "But how can we get through the early years when a single currency is in place without a well-designed federal budget? It Will be an extremely dangerous corner to turn".

Além de encontrar forte oposição na política interna dos países, a proposta de federalização fere a soberania nacional porque, ainda que não através do processo eleitoral, de imediato os governos locais perderiam poder decisório. $\mathrm{Na}$ verdade, a federalização strictu sensu dependeria de centralização do poder político ou de concessão de maiores poderes ao Parlamento Europeu.

Assim, há duas posições conflitantes. De um lado, a Alemanha e os países do Benelux (Bélgica, Holanda e Luxemburgo) defendem a federalização da Europa, sugerindo que a integração fiscal contribuiria para a adequação aos critérios de Maastricht. De outro, a França e o Reino Unido, defensores do Estado-nação e da soberania nacional, argumentam que aceitar a federalização seria abrir mão da soberania em favor da UME.

A conciliação entre os objetivos da UME e dos governos nacionais depende da difícil harmonização entre economia e política também a nível das relações inter- 
nacionais. A sobrevivência da UME depende de que ela não seja motivo de fratura da UE. Dado que poucos países - inclusive a Alemanha — satisfazem atualmente os critérios de qualificação para a UME, surgiram dúvidas sobre um abrandamento dos requisitos e a estabilidade de um processo que alguns consideram demasiado rápido. Argumenta-se que apenas uma minoria de países estará apta a qualificarse e que a admissão de alguns países na UME dificulta a manutenção do mercado comum e da coesão política europeia porque os países que se agruparem para formar a moeda única tenderão a agir em blocos chocando-se com aqueles fora da UME. Esse é justamente o receio de De Grauwe (1996), para quem o cumprimento dos critérios de Maastricht poderá ocasionar a divisão da Europa: "A significant number of countries that today lacks the anti-inflationary credibility, may actually find it extremely difficult, if not impossible, to converge to the union members as long as they are left out. Such a situation Will be very divisive to the European Union. This division of the European Union Will create problems not only for the countries left out, but also for those Who start the union".

Tal fato aumenta os conflitos que envolvem a UME já atordoada com a dificuldade de estabelecer metas com grandes disparidades econômicas entre os países. De Grauwe (1996: 1092) exemplifica essa fragilidade: "For example, when a negative demand shock hits one or more countries while leaving the other members intact, the pressure on the central bank of the union to accommodate with a more expansionary monetary policy Will be strong. This pressure Will be all the more intense as the countries negatively affected by the demand shock lack the flexibility (wages, prices, labour mobility) to adjust. The countries not affected by the negative demand shock, however, arc likely to resist this pressure to accommodate by monetary expansion. As a result, the asymmetric shock Will most likely lead to intense conflicts about the appropriate stance of monetary policies in the union".

\section{A ESTABILIDADE DO CÂMBIO}

A prescrição de política cambial da UME, de manutenção de níveis estáveis de câmbio dentro de determinada faixa de variação, coaduna-se com a restrição ao uso das políticas fiscal e monetária para fomentar crescimento econômico. Mais que isso, coaduna-se com a crença presente em vários autores ${ }^{5}$ de que taxas de câmbio fixas promovem maior disciplina fiscal que taxas de câmbio flexíveis. Embora o sistema de "bandas" seja misto e conjugue virtudes e limitações dos regimes fixo e flexível, a determinação da banda, em geral, segue o argumento de que, sob taxas de câmbio fixas, a condução de uma política fiscal frouxa geraria problemas de balanço de pagamentos, o que induziria o policy maker à austeridade fiscal para evitar rupturas nas regras do câmbio e os custos políticos decorrentes.

Há, contudo, divergência teórica quanto ao que seria o sistema de câmbio

${ }^{5}$ Aghevli et al. (1991), Frenkel et al. (1991) e Giavazzi \& Pagano (1988). 
idealmente compatível com a austeridade fiscal e monetária até porque, tanto com taxas fixas como com taxas flexíveis, há custos para o comportamento imprudente. O que parece diferir é a distribuição intertemporal desses custos. Se a taxa é fixa, a inconsistência das políticas se manifesta com queda de reservas e dívida explosiva, isto é, os custos de uma política fiscal ou monetária frouxa levam mais tempo para aparecer e, quando aparecem, frequentemente exigem uma mudança de curso mais drástica, com implicações para a credibilidade do sistema. Se a taxa é flexível, a inconsistência manifesta-se através de movimentos da taxa de câmbio e, sendo os ajustes automáticos, indicam rapidamente a necessidade de apertos fiscais. Por essa razão, Friedman (1984: 68) postula que a taxa de câmbio deve ser flexível para sustentar uma política monetária exógena e balizada pela taxa de crescimento, evitando-se que a política cambial seja utilizada para fomentar emprego e comércio: "Há somente dois mecanismos consistentes com um mercado e um comércio livres. Um deles é um padrão ouro internacional e completamente automático. O outro é um sistema de câmbio livremente flutuante, determinado no mercado por transações privadas sem a intervenção governamental".

Uma evidência empírica interessante dessa dificuldade de sustentação é que a margem de flutuação passou de 2,25\% em 1991, quando o Tratado de Maastricht foi concluído, para 15\% em 1997. Além disso, países como a Itália e a Inglaterra chegaram a abandonar esse mecanismo de taxa de câmbio ${ }^{66}$. Contudo, a manutenção de taxas de câmbio estáveis dentro de determinadas margens de flutuação, por pelo menos dois anos antes da avaliação, ainda constitui uma das condições para adesão à UME.

Assim, embora o reconhecimento de que taxas fixas per se não induzem disciplina fiscal esteja presente na exigência de adequação aos outros critérios, essa política cambial fez emergir as mesmas críticas já formuladas às políticas fiscal e monetária da UME: efetividade e sustentabilidade. Ressurgiu, então, a Teoria da Área de Moeda Ótima (AMO), que passou a dividir-se em duas abordagens: a "velha teoria" representada pelos estudos realizados na década de sessenta - Mundell (1961), Mckinnon (1963) e Kennen (1969) —e a "nova teoria” também denominada "nova visão" que surgiu com os trabalhos veiculados a partir da década de 80 - Barro \& Gordon (1983), Giavazzi \& Pagano (1988), Mélitz (1988) e De Grawe (1996), entre outros.

De acordo com a "velha teoria taxas de câmbio valorizadas concorrem para a estabilidade de preços, mas, por outro lado, impõem limites ao crescimento ao aumentarem o déficit em conta corrente e agravam as desigualdades regionais, dificultando a própria manutenção da política cambial. Assim, a união monetária de países com diferentes estruturas de produção e emprego e sem perfeita mobilidade da mão-de-obra está sujeita a choques assimétricos, que se traduzem no fato de que algumas regiões podem ser atingidas por quedas de demanda e outras não. Neste caso, para a região atingida, a política cambial mais adequada requereria

\footnotetext{
${ }^{6}$ A Itália regressou ao mecanismo de câmbio em 1997.
} 
uma desvalorização do câmbio para proteger o nível da produção, enquanto, para a área não atingida, não seria preciso realizar alterações no câmbio. O que se questiona é a unicidade do câmbio na Europa, pois tendo em conta as disparidades de produto e emprego, o ideal poderia ser o estabelecimento de políticas cambiais distintas para as diferentes áreas ${ }^{7}$. Ou seja, a AMO discute qual seria a Área de Câmbio Ótima para a Europa.

Além disso, permanece ainda pouco clara a questão de quando e com que paridade as obrigações em moeda nacional deverão ser convertidas em uma moeda supra-nacional e de como ficarão as relações entre os países participantes da UME e aqueles que permanecerão, ao menos temporariamente, excluídos. Esses temores se traduzem em ameaça de perturbações no mercado de câmbio. Por outro lado, os países excluídos do euro poderiam exigir maiores transferências orçamentárias para reduzir sua trajetória de adequação aos critérios.

A manutenção da taxa de câmbio também tem consequências políticas. Se todos os países fossem bem sucedidos na adequação aos critérios da UME, de acordo com Funke \& Kennedy (1997: 2), a moeda europeia poderia suplantar o dólar como reserva mundial de valor: "this paper [...] argued that several factors could contribute to the euro becoming an international currency in the future and a competitor to the US dollar in this respect".

Contudo, a possibilidade de fortalecimento do euro seria descartada com a inclusão de moedas europeias mais fracas, implicando o posicionamento do euro entre a lira e o marco e no fortalecimento da posição da Alemanha como determinante da política econômica. Para Herz \& Róger (1992): “There is a wide consensus among policy makers that the European Monetary System (EMS) — in contrast to the intentions of its founders - has developed in to an asymmetric, fixed exchange rate system with Germany being the center country".

A abordagem da "nova visão" também critica a capacidade das medidas que vêm sendo tomadas de assegurar a estabilidade da UME, mas enfatiza a questão da credibilidade. De acordo com esta teoria, os dirigentes deveriam preocupar-se com as diferenças de preferências por níveis de inflação entre os países integrantes que se fariam representar no Banco Central Europeu (BCE). Para que os países não impusessem uma política monetária distinta da que vem sendo praticada pelo Bundesbank, De Grawe (1996) por exemplo, defende um BCE forte, regido por regras e, portanto, menos sujeito à vontade dos representantes dos governos nacionais no Colegiado do Banco. Além disso, defende também a integração e a convergência do orçamento, o que Impediria que os governos nacionais realizassem políticas econômicas inflacionárias, e reformas nas leis trabalhistas que visam tornar livre o fluxo de trabalhadores.

\footnotetext{
${ }^{7}$ Essa é uma discussão que, a nosso ver, deve anteceder aquela que sustenta a necessidade de um ajuste fiscal ex-ante. Trata-se de saber se a unicidade de tratamento é viável dadas as diferenças estruturais existentes.
} 
Ao analisar a evolução do câmbio efetivo real no período 1990-95 pode-se classificar os países da UME em três grupos:

- Países cujo câmbio sofreu depreciação: Itália (36\%), Reino Unido (12,6\%), Finlândia (14,2\%), Grécia (46,5\%), Espanha (22,5\%) e Suécia (20,5\%);

- Países cujo câmbio sofreu apreciação: Alemanha (11,3\%), Áustria (11,3\%), Bélgica-Luxemburgo (11,7\%), países baixos $(11,9 \%)$ e França $(8,4 \%)$.

- Países que mantiveram o câmbio estável: Irlanda (0,03\%) e Portugal $(0,04 \%)$.

A apreciação do marco decorreu das pressões fiscais geradas pela reunificação da Alemanha, o que motivou a elevação das taxas de juros internas pelo Bundesbank. A França, movida pelo orgulho e pela rivalidade histórica com a Alemanha, valorizou o franco, adotando a política do chamado franc fort. Mas taxas de câmbio valorizadas impõem limites ao crescimento porque aumentam o déficit em conta corrente, qualquer que seja o nível do produto interno. Assim, enquanto a Inglaterra, a Itália e os demais países que desvalorizaram suas moedas viam suas economias adquirirem novo fôlego e suas exportações se recuperarem, a França ficou estagnada, o desemprego cresceu e as pressões internas aumentaram.

\section{A FLEXIBILIDADE DE SALÁRIOS E PREÇOS COMO PRÉ-CONDIÇÃO}

Além dos critérios para harmonização da política econômica mencionados acima, para que sejam alcançados os objetivos da UME, tornam-se necessárias várias reformas estruturais para aumentar a competitividade de mercado dos países membros relativamente a seus parceiros comerciais, principalmente Japão e EUA. Trata-se de medidas que visam aproximar os diferentes países europeus, permitindo o livre fluxo do trabalho e capital. De acordo com a AMO, os países ou regiões que apresentam expressiva divergência no produto e na taxa de emprego e desejam unificação monetária bem-sucedida precisam de flexibilidade de salários, liberalização de comércio entre os países membros, livre movimentação de fatores de produção e integração fiscal (ver Tavlas, 1994).

Quanto às perspectivas de convergência aos critérios de Maastricht, a teoria da "nova visão" argumenta que a saúde econômica da UME dependerá da manutenção das reformas nas leis trabalhistas que visam tornar livre o fluxo de trabalhadores. Para favorecer o livre fluxo de trabalho e de capital, foram estabelecidos acordos no âmbito da UE: (1) no mercado de trabalho, para reduzir os desincentivos institucionais e regulatórios na contratação de empregados ou na busca de emprego por desempregados; (2) no mercado de bens e serviços, para reduzir a regulamentação e aumentar a competição.

No que se refere especificamente à flexibilidade do mercado de trabalho, que devera contribuir para a flexibilização dos salários, prevê-se a incorporação ao Tratado de Maastricht do acordo de Schengen, de 1985, que estabelece a abolição 
gradual dos controles de fronteira. Atualmente, há liberdade de trânsito entre Alemanha, Bélgica, Espanha, França, Holanda, Luxemburgo e Portugal. Contudo, Áustria, Dinamarca, Finlândia, Grécia, Itália e Suécia assinaram o acordo de Schengen, mas não o implementaram integralmente. $O$ governo inglês também tem sérias restrições quanto a conceder autoridade à Corte Europeia de Justiça no que tange a questões de imigração e abertura de suas fronteiras em especial junto à Irlanda.

Ainda para aumentar a flexibilidade do mercado de trabalho, são exemplos os acordos para o estabelecimento da jornada de meio período e para que os advogados dos países membros da UE que desejarem abrir escritórios em outros países membros não tenham mais de provar estarem completamente familiarizados com as leis nacionais do país em que pretendem se estabelecer ${ }^{8}$.

Contudo, depois de aberto o fluxo de capital e trabalho, o movimento de pessoas ficou abaixo do esperado. Tomando a Alemanha como exemplo, percebe-se que é pequena a participação dos estrangeiros oriundos dos países da UE, apenas $1,9 \%$ da população total frente a $11,3 \%$ dos países que não compõem a UE.

\begin{tabular}{cc}
\hline \multicolumn{2}{c}{$\begin{array}{c}\text { População estrangeira da Alemanha } \\
\text { \% da população total }\end{array}$} \\
\hline Turcos & 8,2 \\
lugoslavos & 1,0 \\
Italianos & 0,9 \\
Asiáticos & 0,7 \\
Gregos & 0,5 \\
Poloneses & 0,4 \\
Austríacos & 0,3 \\
Espanhóis & 0,2 \\
Outros & 1,0 \\
\hline Total & 13,2 \\
\hline
\end{tabular}

Fonte: Revista Bem Vindo à Alemanha na Gazeta Mercantil de 10/08/95

A resistência à imigração - em especial a definitiva, já que os trabalhadores tendem a retornar aos seus países de origem depois de algum tempo - pode ser em parte explicada pelo fato de que os benefícios concedidos a imigrantes não substituem a cidadania nacional. Além do custo envolvido na mudança, separação de familiares e adaptação a condições diversas como idioma, religião e cultura, ser estrangeiro não confere condições semelhantes às do cidadão nacional, inclusive em virtude de discriminação racial e religiosa e de resistências corporativistas. Os elevados níveis de desemprego de alguns países incentivam reações da população à entrada de mão-de-obra estrangeira, em especial para postos que exigem maior

\footnotetext{
${ }^{8}$ Ver Financial Times, 22/05/97.
} 
qualificação. As diferenças entre os povos, alimentadas por guerras e disputas às vezes seculares, fornecem a justificativa ideológica para sustentar tais resistências. Este é, sem dúvida, um grande obstáculo ao livre fluxo da mão-de-obra e à convergência da taxa de desemprego entre os países que admitem o livre trânsito de pessoas, conforme apontam Mellors \& Copperthwaite (1990): "Embora pequena pe10s padrões continentais, a Europa possui uma variedade que se manifesta nas características que vão das bases geológicas [...] passando pelo relevo e topografia, até o clima, os solos [...]. Superposta a esta base física variada esta uma paisagem cultural que espelha aquela variedade. Apesar de que a migração tenha sido sempre importante no povoamento dos territórios e na mistura dos grupos populacionais, a Europa reteve dentro de sua área um espantoso elenco de grupos culturais”.

Além disso, o fato de haver significativa diferença entre os níveis dos benefícios da previdência dos vários países europeus e entre as regras que regem a sua concessão não deve ser desprezado como obstáculo ao livre fluxo de mão-de-obra. Como em geral não há equivalência entre a contribuição e o benefício e uma geração custeia os benefícios auferidos pela outra, a população do país que paga mais benefícios a imigrantes tende a reagir à imigração, entendendo que arcara com um ônus adicional. A situação em que a imigração não proporciona um equilíbrio ótimo de Pareto é descrita por Casella (1996): “[...] we have found that if either jurisdiction liberalizes its immigration policy, the equilibrium real incomes of workers Who compete with immigrants must fall in both jurisdictions. Social welfare rises or falls depending on whether immigrants are net fiscal contributors or net fiscal beneficiaries. It is worth emphasizing here that the net incomes of 'workers', i.e., of those compete with immigrants in the labor market, may be reduced even if these workers are net fiscal contributors; in this case, immigration raises 'social welfare', but this welfare gain is not a Pareto - improvement; instead, the gains to one group more than offset the losses to the other. In general, the effects of a more liberal immigration policy in either jurisdiction Will be felt by both because the two are linked through a common labor market. However, we have shown that a central government can, in principle, internalize fiscal externalities through a system of suitably-designed taxes and subsidies".

A suposição de que a flexibilidade da mão-de-obra na Europa deverá permitir a minoração das diferenças entre os países parece otimista, pois sabe-se que em países onde existe livre fluxo de mão-de-obra e a previdência é a mesma, como a Itália por exemplo, não se conseguiu minorar os problemas regionais. Ao contrário, a diversidade tende a tornar-se um empecilho ao livre fluxo da mão-de-obra e à UME, até porque frequentemente se converte em fator de perturbação política, conforme constata Clout (1975): "No nível regional, demonstrações de identidade cultural e até mesmo sentimentos autonomistas têm emanado de bascos e bretões, cornualeses e córsegos, valoneses e galeses, e membros de outros grupos minoritários, preocupados com seu bem-estar econômico, sua sobrevivência cultural e a natureza de sua relação com as administrações centrais".

Relativamente ao movimento de capitais, ainda que sejam vencidas as resistências à federalização, o aparato legal também precisaria sofrer alterações, elimi- 
nando-se entraves das legislações de cada país. O fato de não existirem normas regulatórias únicas e de prevalecer a legislação própria de cada país fez com que líderes da indústria buscassem um estatuto único que permitisse que as companhias com operações em mais de um país membro fossem governadas por uma única lei, aplicável a todos os países da $\mathrm{UE}^{9}$, numa tentativa de romper os 25 anos de impasse quanto às propostas de adoção de um estatuto corporativo unificado. A importância de iniciativas como essa é destacada por Casella (1975): “ [ ...1 the demand for legal services, the requirements in terms of formalism, sophistication, rapidity of enforcement, cost, depends on the economic role of each individuals in different countries engaged in the same economic activity come into contact and develop a system of laws attuned to their needs, and in large part independent of national laws. As they do so, they create the institutional basis for further expansion of trade. Private trade leads to the creation of a new, supranational jurisdiction, and starts the process towards further international integration. International commercial arbitration is a concrete and important example of the link between economic transaction and the creation of international coalitions of private individuals, the emergence 'from the bottom' of international jurisdictions".

Ainda assim, a atual descentralização política impõe limites à existência de normas regulatórias e expõe as empresas a normas díspares, pois cada governo nacional possui legislação própria. Os países integrantes do mercado único ainda dispõem da capacidade de impor normas domésticas que limitam a venda de alguns serviços como contas correntes remuneradas (interest-bearing current accounts) e algumas empresas cobram prêmios mais elevados ou simplesmente não prestam serviços a consumidores não-residentes no país onde estão sediadas. Segundo o comissário europeu para Serviços Financeiros, apesar da liberalização do comércio entre-fronteiras, muitas empresas do setor não estão vendendo serviços aos países vizinhos.

Além disso, a guerra fiscal, por exemplo, pode resultar em queda de receitas para a UE. Muitos governos nacionais ofereceram subsídios não previstos na UE para manterem investimentos no próprio país. Pode-se citar a concessão de subsídios pelo governo da Saxônia ${ }^{10}$ para que a Volkswagen instalasse fábrica no seu país, apesar de todas as reclamações da Comissão Europeia.

Neste contexto, inserem-se também as resistências por parte daqueles que perderiam espaço quando fossem disseminados serviços que atualmente fornecem de forma exclusiva ou preponderante. Os esforços para realizar a união por meio eletrônico ${ }^{11}$ das bolsas de valores de Paris e Frankfurt - as maiores da Europa depois de Londres - contrariam os interesses londrinos, pois a cidade tende a perder importância como centro financeiro da Europa.

\footnotetext{
${ }^{9}$ Ver Financial Times, 14/05/97.

${ }^{10}$ Ver Financial Times, 10/8/96.
} 


\section{CONCLUSÃO: PERSPECTIVAS E DIFICULDADES DE IMPLEMENTAÇÃO}

Para os defensores da UME, a busca da eficiência somente seria possível através da aproximação de uma economia de mercado, com flexibilidade no mercado de trabalho e no fluxo de capitais. Este fato seria comprovado pela evolução dos indicadores econômicos e financeiros de muitos países já adaptados às metas do Tratado de Maastricht. Na verdade, a evolução dos indicadores tem dado suporte à tese de que muitos países cumprirão as metas estabelecidas. De acordo com o Relatório de Coesão, publicado pela Comissão Europeia, as disparidades entre Irlanda, Espanha, Portugal e Grécia e os demais países da UE diminuíram no período de 1983 a 1995. O PIB per capita dos quatro países aumentou de $66 \%$ da média da UE em 1983 para 76\% em 1995.

Nos últimos anos, a UE como um todo obteve um desempenho melhor do que o do Japão, com maior taxa de crescimento do PIB acompanhada de estabilidade nos preços e de ajuste nas contas públicas. Embora a dívida pública bruta da UE seja elevada e esteja acima da dos EUA, e da exigência do critério de Maastrich, está abaixo da japonesa. Os países-membros deverão empreender uma estratégia fiscal de médio prazo para conter o crescimento do déficit com ajustamento das despesas às receitas e, consequentemente, reduzir a relação dívida-PIB. São previstos, já para o próximo ano, expressivos cortes dos gastos para garantir que o déficit fique abaixo de $3 \%$ do PIB em 1997. As taxas de juros de longo prazo também estão diminuindo seu diferencial vis à vis à taxa de juros da Alemanha.

Os opositores da UME, no entanto, afirmam que este não é o único caminho capaz de atingir os objetivos pretendidos e citam contra-exemplos da história econômica mundial. Nos Estados Unidos, a taxa de desemprego decresceu apesar da abertura da economia. É certo que o mercado de trabalho é flexível, mas o país adotou estratégia oposta à da UME: política fiscal expansionista e política monetária duríssima já no início dos anos 80 . O resultado é que a economia dos EUA está em expansão — as exceções foram os anos de 1982 e 1991 — e com inflação declinante.

Assim, para a tradicional teoria AMO, a convergência dos indicadores econômicos e financeiros não é nem necessária nem suficiente para o sucesso da UME. Não é necessária porque, de fato, o caminho da UME não parece ser o único capaz de atingir os objetivos pretendidos. Além disso, relativamente à suficiência de adequação aos critérios da UME, ainda que fossem vencidas as resistências iniciais, a UME não seria estável porque a adequação aos critérios não garante que sejam atingidos, de forma sustentável, os objetivos de estabilização, crescimento e redução das desigualdades regionais. Em outras palavras, a UME não seria estável porque: as regras de mercado não seriam eficientes para evitar crises econômicas; a centralização orçamentária não seria eficiente para promover simultaneamente a estabilização e a redução das desigualdades regionais; e não seria possível obter as quatro pré-condições necessárias - capacidade de implementação de regras monetárias rígidas pelo Banco Central, coalizão política em torno do ajuste fiscal, livre fluxo de mão-de-obra e 
de capital, e estabilidade do câmbio em determinada faixa de variação — as quais dependem de aspectos estruturais das economias e de fatores políticos.

Neste sentido, De Grauwe (1996) afirma: “ (...) prior convergence of inflation rates is not sufficient to form a monetary union. Two countries may have the same rates of inflation (Japan and Germany for example) and yet be structurally so different that a monetary union between would be suboptimal. Or take the example of Belgium and Germany".

O entrave à integração representado pelas disparidades regionais fica mais evidente quando se analisa os mercados de trabalho e de capital. A legislação da área até o momento não parece ser suficiente para sobrepor os aspectos linguísticos, religiosos, raciais e culturais presentes na diversidade europeia e as resistências corporativistas.

$\mathrm{Na}$ verdade, quando se discute a estabilidade dos critérios de Maastricht e sua suficiência na promoção do desenvolvimento europeu, a questão que se coloca é se a UME pode ou não propiciar uma situação "ótima de Pareto" para todos os governos nacionais, e se isto é ou não um impedimento a sua estabilidade. Do ponto de vista político, alguns avanços importantes para UME têm sido observados após Maastricht, tais como a ampliação dos poderes do Parlamento Europeu, a instauração da cidadania europeia com direito a voto nas eleições municipais e nas europeias para os residentes comunitários nos países da União em que habitarem e a criação de um Comitê das Regiões, constituído por representantes das autoridades locais e regionais dos Estados-membros, que é consultado pelo Conselho ou pela Comissão antes de ser adotada qualquer decisão sobre as regiões.

Os avanços indicam que, embora a UME não constitua um "ótimo de Pareto" para todos e alguns países sejam beneficiados enquanto outros são prejudicados, a integração poderá ser apoiada se não houver alternativa de sobrevivência econômica para os excluídos ou se o prejuízo provocado pela exclusão for maior que o da adesão.

No entanto, no que diz respeito à suficiência da adequação aos critérios para que seja atingido o objetivo de maior desenvolvimento dos países europeus, se a UME não for um "ótimo de Pareto", ainda que seja estável, provavelmente não proporcionara igual crescimento a todos os países. Então, a pergunta que se coloca é se o papel do policy maker deve ser o de tão-somente perseguir a estabilização de preços, desprezando o crescimento do produto e do emprego como meta de política econômica. Ou, em outras palavras, se as variáveis nominais - preços e câmbio - estiverem sob controle, o mercado se auto-ajustará?

\section{REFERÊNCIAS}

AGHEVLI, B., KHAN, M. \& MONTIEL, P. (1991) "Exchange rate policies in developing countries: Some analytical issues", IMF Occasional Paper no 78. Washington, DC, IMF), mar.

BARRO, R. \& GORDON, D. (1983) "Rules, discretion and reputation in a model of monetary policy" , Journal of Monetary Economics, jul. 
BARRO, R. J. (1996) Getting It Right: Markets and Choices in a Free Society. Cambridge, Mass., MIT Press.

CARVALHO, F. J. C. (1995) "The independence of central banks: a critical assessment of the arguments”, Journal of Post-Keynesian Economics, winter 1995, vol. 18, no 2.

CASELLA, A. (1996) "On market integration and the development of institutions: The case of international commercial arbitration”, European Economic Review, 40 (1996) 155-186.

CLOUT, H. (1975) "Regional development in Western Europe", in: HUGH, C. (org.) Regional development in Western Europe. London, John Wiley.

De GRAUWE, P. (1992) “German monetary unification”, European Economic Review, n. 0 36, NorthHolland.

(1996) “Monetary union and convergence of economics.” European Economic Review, no 40, North-Holland.

FINANCIAL TIMES, diversos nimeros.

FRENKEL, J., GOLDSTEIN, M. \& MASSON, P. (1991) "Characteristics of a successful exchange rate system”, IMF Occasional Paper no 82. Washington, DC, IMF, jul.

FRIEDMAN, M. (1984) Capitalismo e liberdade. Säo Paulo, Abril Cultural.

FUNKE, N. \& KENNEDY, M. (1997) “International implications of European Economic and Monetary Union”, OECD Working Paper n.0 174.

GAZETA MERCANTIL, diversos números.

GIAVAZZI, F. \& PAGANO, M. (1988) “The advantage of tying one's hands: EMS discipline and Central Bank credibility”, European Economic Review, no 32.

GOMES. G. M. (1997) “Desenvolvimento e Politica Regional na Uniäo Européia”, Texto para Discussäo n. 0 483, IPEA, maio.

GOODHART, C. A. E. (1996) “European Economic Integration.” European Economic Review, no 40.

(1994) "Game Theory for Central Bankers: A Report to the Governor of the Bank of England", Journal of Econometric Literature, vol. XXXI.

HAGEN, J. Von \& SÜPPEL, R. (1994) “Central Bank constitutions for federal monetary”, European Economic Review, no 38.

HERZ, B. \& RÖGER, W. (1992) “The EMS is a greater Deutschmark area European Economic Review, n. 036 .

HOELLER, P. \& LOUPPE, M. \& VERGRIETE, P. (1996) "Fiscal Relations within the European Union “, OCDE Working Paper no 163.

ISAAC, A. G. (1993) “Is there a natural rate?” Journal of Post-Keynesian Economics, vol. 15, no 4, summer.

KENNEN, P. (1969) “The theory of optimum currency areas: an eclectic view”, in: MUNDELL, R. \& SWOBODA, A., Monetary problems of the international economy. Chicago, University of Chicago Press.

LUCAS, Jr., R. E. \& SARGENT, T. J. (1981) “After Keynesian Macroeconomics”. In LUCAS, Jr., R. E. \& SARGENT, T. J. (eds) (1981) Rational Expectations and Econometric Practice. Minneapolis, University of Minnesota Press.

McKINNON, R. (1963) “Optimum currency areas”, American Economic Review, sep.

MÉLITZ, J. (1988) "Monetary discipline, Germany and the European Monetary System: A synthesis “ , in: GIAVAZZI, E, MICOSSI, S. \& MILLER, M., (eds.), The European Monetary System, Cambridge, UK: Cambridge University Press, 1988.

MELLORS, C. \& COPPERTHWAITE, N. (1990) (eds.) Regional policy. Spicers European Policy Reports. London, Routledge.

MUNDELL, R. (1961) "A theory of optimal currency areas", American Economic Review.

PASSARIDES, C. A. (1980) "British Government Popularity and Economic Performance", The Economic Journal, no 90.

PATINKIM, D. (1985) "Flexibilidade de preços e pleno emprego", in: Análise Macroeconômica: Leituras Selecionadas. São Paulo, Brasil: E. Shapiro, Atlas.

RICARDO, D. (1821). Princípios de Economia Política e Tributação. São Paulo, Nova Cultural. 
SHAH A. (1997) “Federalismo Fiscal e Governança Macroeconômica. Teoria e Prática”. Apresentado na Conferência Internacional em Descentralização, Relações Fiscais Intergovernamentais e Governança Macroeconômica, Brasília, DF, 16-17 jun.

TANZI, V. (1996) Taxation in an Integration World. Washington, DC, Brookings.

TAVLAS, G. (1994) “The theory of monetary integration”, Open Economies Review, vol. 5, no 2.

TER-MINASSIAN, T. (1997) “Descentralização e Disciplina Fiscal. Direções Futuras” Apresentado na Conferência Internacional em Descentralização, Relações Fiscais Intergovernamentais e Governança Macroeconômica, Brasília, DF, 16-17 jun.

TUCHSCHERER, T. (1981) “The unnatural 'natural' rate of unemployment”, Journal of Post-Keynesian Economics, vol. 4, no 1.Brazilian Journal of Political Economy, vol. 20, no 1 (77), January$\mathrm{March} / 2000$ 